\title{
Brazilian Design: Parametric modeling as memory of vernacular artifacts
}

\section{SIGRADI2018 TECHNOPOLITICAS \\ xxii congresso da sociedade iberoamericana de gráfica digital 22th conference of the iberoamerican society of digital graphics 07|08|09|novembro|2018 iau usp | são carlos | sp br}

\author{
Rafael Mourão Fiuza \\ Universidade Federal do Ceará | Brazil | rafaelmfiuza@gmail.com \\ Leonardo Luna de Melo Jorge \\ Universidade Federal do Ceará | Brazil | leolmj|@hotmail.com \\ Hugo Guimarães Sampaio \\ Universidade Federal do Ceará | Brazil | hugosampaio@design.ufc.br \\ Daniel Ribeiro Cardoso \\ Universidade Federal do Ceará | Brazil | danielcardoso@ufc.br
}

\begin{abstract}
With the consolidation of digital media, we have seen the expansion of documentation and design modes. Two-dimensional representation was the main mean of communication in projects, however, in a process whose design of the form presents complexity, are no longer considered as adequate solutions. The parametric documentation of the vernacular knowledge of Icapuí boat production carries with it part of the immateriality of the step-bystep of a traditional process, resulting in the description of the complexity of the boat shapes. This article tries to affirm the power of the digital processes for the maintenance of the memory.
\end{abstract}

Keywords: Typology; Parametric Design, Heritage, Vernacular Design, Boats.

\section{INTRODUÇÃO}

Com a consolidação dos meios de base digital no Design, temos observado a ampliação dos modos de leitura, documentação e de projetação. Os modelos tridimensionais, paramétricos, e os protótipos físicos proporcionaram uma outra forma de representação, mais própria à documentação e à comunicação. Nesse contexto temático, o artigo propõe uma reflexão sobre as contribuições das TICs - Tecnologias da Informação e Comunicação - como meio próprio à documentação, tradução de um sistema de formação e preservação da memória de um artefato vernacular. Para tanto, o objeto de estudo escolhido foram os botes a vela artesanais, mais especificamente os Botes triângulo - típicos do município de Icapuí, cidade localizada no litoral leste do Ceará, onde a pesca artesanal foi elemento norteador de sua fundação e ainda constitui cultura viva. Segundo Araújo e Duarte Jr. (2014), o tradicional acervo naval cearense é tido como patrimônio cultural da humanidade, tesouro que ainda resta desconhecido. De acordo com Braga (2013), o conhecimento empírico do ofício de construção dos barcos é transmitido, ao longo do tempo de pai para filho, ou por pessoa ou parente carpinteiro, ou simplesmente por "ver e fazer".

Percebeu-se que esse conhecimento de construção das embarcações segue um conjunto de regras de composição, que são equalizadas pelas necessidades de engenharia náutica; os processos artesanais de carpintaria e as individualidades do binário artesãocontratante. O barco, portanto, se mostra elemento histórico, cultural, social e econômico do município.

\section{DESIGN BRASILEIRO}

"Pois se conseguirmos detectar, ao longo do espaço brasileiro, as atividades artesanais e influenciá-las, estaremos criando um design novo, o design brasileiro" (Magalhães, 1977 apud Anastassakis, 2007)

Para Aloísio Magalhães (1997) dentro do conceito clássico e ortodoxo da palavra, não existe propriamente artesanato no Brasil. O que parece existir é uma disponibilidade imensa para o fazer, para a criação de objetos. Sendo assim uma atividade que quer entrar na trajetória do tempo e evoluir na direção da maior complexidade e de resultados mais efetivos. "Em outras palavras, o artesão brasileiro é basicamente um designer em potencial, muito mais do que propriamente um artesão no sentido clássico" (Magalhães, 1997).

\section{BOTES A VELA}

Conforme Braga (2013), as embarcações tradicionais a vela existentes no Ceará distribuem-se pelos $573 \mathrm{~km}$ do litoral do estado ( $8,5 \%$ do litoral brasileiro). Segundo esse autor a frota pesqueira a vela existente no Ceará é composta por jangadas, paquetes, canoas, botes e seus subtipos ou variantes. Com efeito, de acordo com Araújo e Duarte Jr. (2014) a frota cearense possui apenas quatro tipologias náuticas: canoa; jangada; paquete e bote a vela. Sendo essa última tipologia o foco de estudo do presente trabalho, mais especificamente os botes triângulo do município de Icapuí-CE. A distribuição dos botes no Ceará se concentra principalmente em três municípios, sendo Icapuí no litoral leste o de maior representação, com 317 Unidades. (Braga, 2013) 
Braga afirma que:

Distinguem-se dois tipos de botes no Ceará, que nas praias são popularmente denominados de bote triângulo e bote bastardo se tem mastro removível ou fixo respectivamente. Os botes triângulos são predominantes no município de Icapuí, com maioria na praia de Redonda, e os botes bastardos de Camocim, que pleiteiam o seu reconhecimento de patrimônio cultural móvel desta cidade. (Braga, 2013)

No ESTATPESCA (IBAMA, 1998 apud Braga, 2013), os botes são descritos como embarcações a vela, com casco de madeira dotado de quilha, de convés fechado sem casaria e com comprimento total inferior a 11 metros. Segundo Castro e Silva, 2004 apud Braga, 2013, os botes a vela são as maiores embarcações veleiras encontradas no litoral cearense.

\section{BOTE TRIÂNGULO}

Os botes triângulo predominam no município de Icapuí e usam vela triangular entralhada ao mastro removível. Os moradores mais antigos afirmam que até o início da década de 60, tinham duas velas com formato diferente da triangular. Nos anos de 1995 e 2006, o município contava com 241 e 317 unidades, respectivamente (IBAMA, 1996; 2008 apud Braga, 2013) sendo a praia de Redonda a localidade onde se registra a maior concentração deste tipo de bote, com 179 no ano de 2007 (BRASIL, 2009 apud Braga, 2013).

\section{METODOLOGIA}

Para o processo de produção do conhecimento foram adotados o método indutivo e o estudo de caso, como descrito em Dresch, Lacerda \& Antunes Jr (2015). Bem como a abordagem da arquitetura vernacular proposta por Cardoso (2010), fazendo uso de tais referências para documentação de artefatos vernaculares como guia para instituições implicadas com cultura e patrimônio.

Partindo de visitas de campo, primeiramente foram feitas entrevistas para entender as partes principais do barco e como essas compõem seu processo de construção. Posteriormente, com o olhar mais direcionado, efetuaramse levantamentos através de medições, fotogrametria e fotografias das embarcações. A partir da metodologia foi feito o levantamento de três botes triângulo no total. Denominados como: Caciqui; São Geraldo; Maresia. (Figura 1).

Em seguida compilou-se os dados adquiridos para descrição, caracterização e documentação do processo de produção do artefato, formalizando a gramática de formação em algoritmo. Com efeito, utilizou-se como recurso computacional de representação a modelagem paramétrica no software Grasshopper. Posterior ao algoritmo, uma tabela foi feita listando todos os parâmetros usados na construção do barco, e cada barco modelado ganhou uma ficha que listava todos seus parâmetros. Os parâmetros foram organizados seguindo uma hierarquia na qual as partes eram compostas por peças, e as peças possuíam qualidades, ou parâmetros numéricos como no exemplo: Proa (R) -> Talhamar (Rt) -> Altura (Rth). Por fim, busca-se implementar e validar 0 sistema através de novas entrevistas com os mestres carpinteiros das embarcações.

Optou-se pela formalização dos dados na interface de modelagem paramétrica devido seu potencial de documentar não apenas o objeto de estudo, mas suas etapas de construção. Essa camada imaterial do processo está presente na descrição lógica das etapas na codificação do algoritmo, pois o caráter sequencial desse tipo de abordagem exige que todas as formas e processos sejam descritos claramente por ferramentas geométricas e matemáticas. Portanto, de acordo com os objetivos
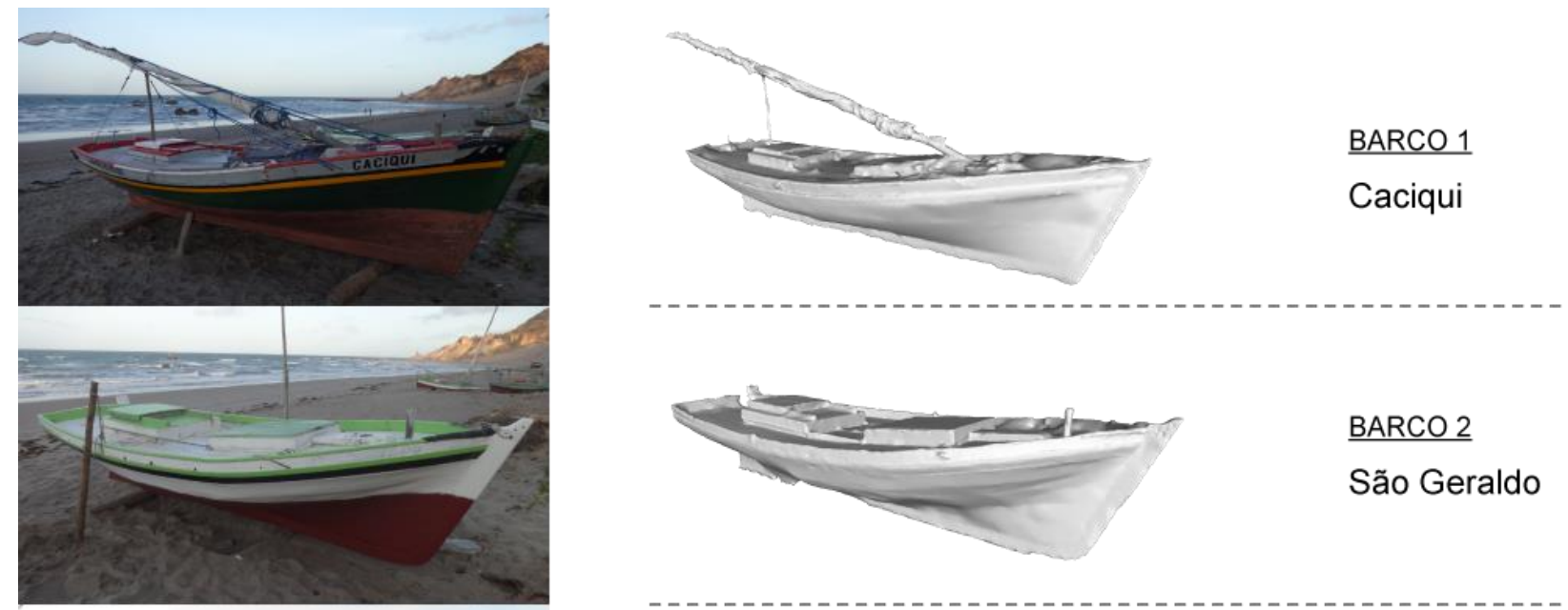

BARCO 2

São Geraldo
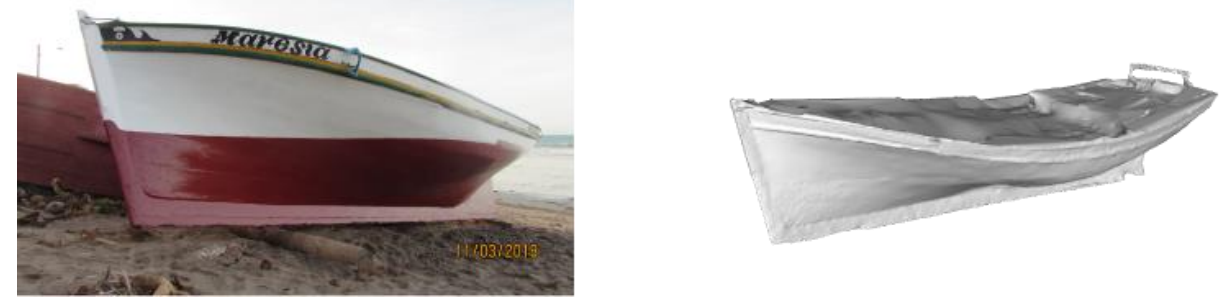

BARCO 3

Maresia

Figura 1: Modelagem 3D feita por fotogrametria. Fonte: autores. 


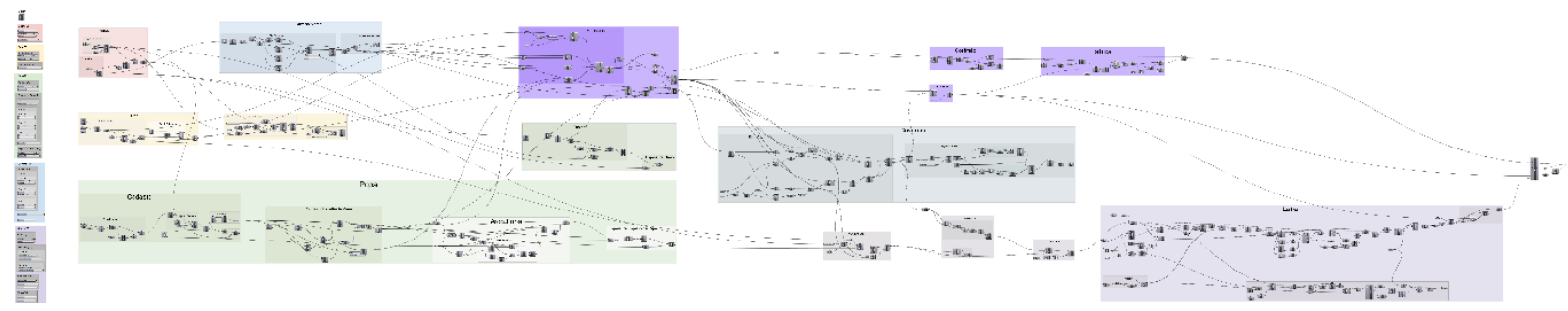

Figura 2: Código representando passo-a-passo da construção lógica dos botes. Fonte: autores.

documentais da presente pesquisa, modelagens não paramétricas se mostraram insuficientes, pois suas abordagens encaravam o objeto como modelo e não como conjunto de regras e processos, limitação que já não se encontra na modelagem paramétrica. Ou seja, ao se descrever em apenas um algoritmo o encadeamento lógico é possível alcançar os diversos modelos, apontando que tal abordagem é apropriada para documentação de culturas locais por representar grande quantidade de informações, extrapolando as possibilidades da catalogação de modelos (Figura 2).

\section{RESULTADOS}

A representação da linguagem vernacular dos botes de Icapuí através de método computacional como documentação do patrimônio material e imaterial é, portanto, o principal produto. Isso por considerar não apenas o objeto físico, mas a imaterialidade do processo tradicional, resultando na descrição e formalização da lógica de construção dos barcos e a demonstração gráfica dessa linguagem com o desenvolvimento de algoritmos.

\section{CONSTRUÇÃO DO BOTE}

A construção do bote foi documentada com enfoque nas linhas de construção da forma do barco, buscando compreender o processo manual e seu rebatimento morfológico. As peças listadas não representam a totalidade de madeiras encontradas no barco acabado e em uso, mas sim as que balizam a construção de sua forma. Esse enfoque também teve rebatimento na documentação dos processos que geram os desenhos das peças, ora por meio de gabaritos, ora por meio de formas emergentes do processo manual. Gursoy diz acerca da descoberta e projetação por meio de materiais que "as incertezas inerentes nos modelos físicos, tanto por causa de movimentos acidentais ou pelo comportamento imprevisível dos materiais, levam a geração de novas ideias no processo de design" e o processo de descobertas dos desenhos das peças juntamente ao uso de gabaritos maleáveis como vergalhões de aço são bons exemplos.

A documentação consiste em 8 etapas descritas abaixo (Figura 4):

A parte inicial é a Quilha (Q), que irá estruturar o bote e definir o seu comprimento, trabalhando como espinha dorsal (etapa 1).

Posteriormente, na parte Proa $(R)$, é fixado o Talhamar (Rt) por meio de uma peça chamada de Volta de Proa $(R v)$, que devido sua grande solicitação estrutural de impacto frontal com as ondas, deve ser cortado de uma raiz buscada no mato cuja curvatura seja a desejada para o barco, garantindo sua resistência por meio das fibras naturais. As junções das diferentes peças são feitas segundo Braga (2013): "em perfeito encaixe por meio de emendas denominadas dente de cão aos quais são fixados o coral e o contracoral, definindo a proa" (etapa 2).

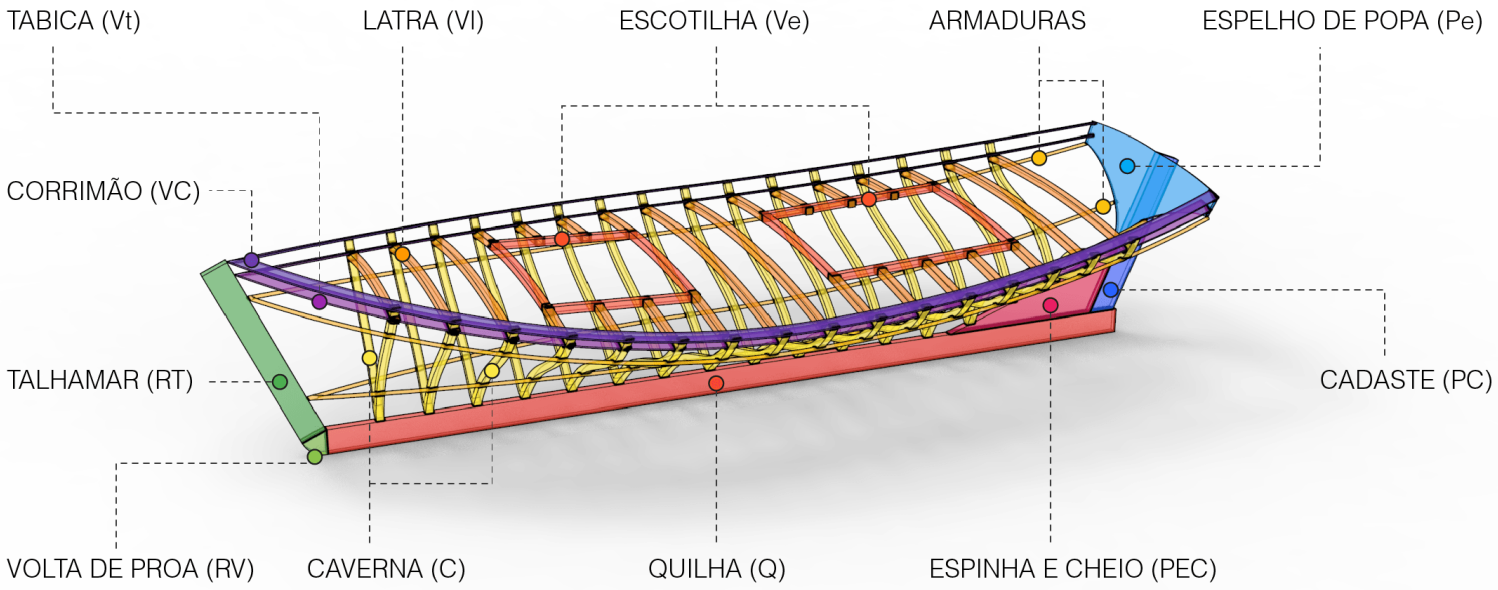

Figura 3: Partes do bote. Fonte: autores. 
Já na parte no lado oposto da proa, a Popa $(P)$, é levantado o Cadaste $(P C)$ travado pela Espinha definindo assim a área do Cheio $(\mathrm{Pec})$. No cadaste é afixado o Espelho de Popa $(\mathrm{Pe})$ cujo formato varia de acordo com cada mestre carpinteiro de barcos, pois suas curvas, que são importantes para definir forma do casco, são cortadas seguindo gabaritos, e cada mestre tem seu conjunto de gabaritos. O cadaste vai suportar as fixações da ponta do leme. (Braga, 2013) (etapa 3)

Posterior a popa e proa, e com a estrutura já escorada, se inicia a parte das Cavernas (C) com as Cavernas Mestras $(\mathrm{Cm})$, colocadas no centro da quilha com espaçamento que pode variar entre $30 \mathrm{~cm}$ a $40 \mathrm{~cm}$. Essas peças de mesmo formato são fundamentais para a superfície do casco, pois sua curvatura é um dos definidores de quão "cavada" ou quão larga será sua porção inferior, características fundamentais para o uso do barco. Barcos "cavados" são mais velozes e barcos de base mais larga são mais estáveis e aguentam mais peso. O formato da caverna mestra, assim como o espelho de popa, também é obtido com um gabarito, porém dependendo de qual uso o barco terá pode sofrer alterações no momento do corte por meio de recursos geométricos para melhor adaptar ao seu futuro uso. Também são as cavernas mestras que definem a largura da boca do barco, a qual usualmente segue a proporção de $1 / 3$ do comprimento, podendo variar conforme desejo do cliente. (etapa 4)
Em seguida, de acordo com Braga: são colocadas as armaduras [...] que consistem em ripas afixadas nas cavernas iniciais, de proa a popa no contorno de alinhamento longitudinal do casco, para que seja possível a inserção das cavernas modeladas por vergalhão de ferro que lhe dão o formato exato. As armaduras têm a finalidade de dar a forma de contorno de cada uma das cavernas no processo de construção do casco.

É nesse momento que toma forma a superfície de extrema complexidade descritiva do casco, e isso por meios manuais e rudimentares, os quais formam as linhas de construção do mesmo. Esse processo de grande sofisticação geométrica e tridimensional torna possível representar uma superfície não-euclidiana, com torções topológicas proporcionadas pela flexibilidade da madeira, a qual muitas vezes tem que ser hidratada por dias para conseguir desempenhar tais movimentos. As armaduras flexionadas, portanto, desenham uma curva a qual pode ser mais aguda, ou mais aberta, resultando também no quão cavado será o casco, dependendo do quão pressionado foi a fixação da armadura (etapa 5).

Com essa linha construída, é possível obter o desenho das demais armaduras através do vergalhão de ferro e com isso toda a estruturação para a materialização da superfície se finaliza (etapa 6).
07

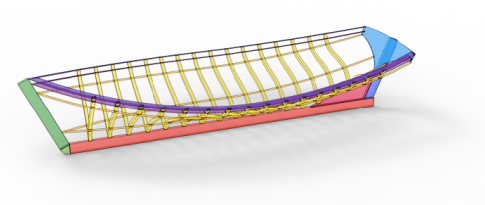

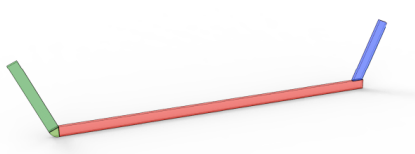

05
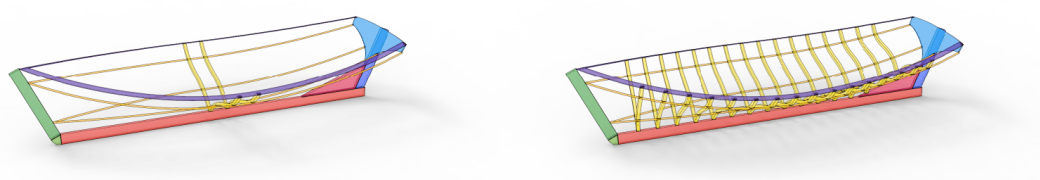

03

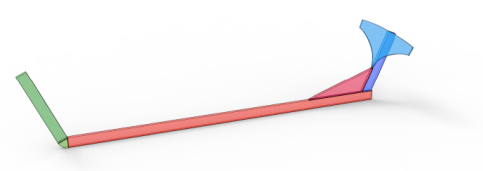

06

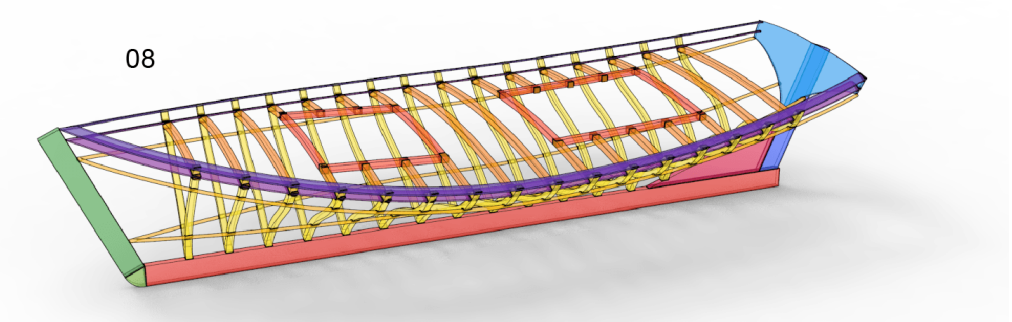

Figura 4: Ordem de construção do bote. Fonte: autores. 
Postas todas as armaduras, uma peça paralela a quilha intitulada de sobrequilha serve como um dos travamentos desse sistema de costelas. Posteriormente, todas as armaduras são presas na parte superior por uma peça chamada de Tabica (Vt) que desenha o contorno superior do barco. Essa é uma das peças mais complicadas segundo o construtor de barcos entrevistado Ismael, pois além de acompanhar perfeitamente a curvatura espacial de topo, deve também ser recortada com precisão para acomodar todas as pontas das cavernas, e assim amarrar a estrutura do barco. Finalizada essa etapa, o barco já está travado e sua estrutura solidarizada (etapa 7).

Em seguida inicia-se a construção da segunda superfície complexa e não euclidiana além do casco, o Convés (V), e seu processo também segue a lógica de linhas construtivas que posteriormente receberão tábuas flexíveis para conformar a curvatura topológica. As peças que desenham a superfície do convés são chamadas
Latras (VI) e tem forma arqueada, com flechas que podem variar de $5 \mathrm{~cm}$ até $35 \mathrm{~cm}$. As latras também comportam as Escotilhas (Ve), que são aberturas para acesso da caverna, parte oca interna do barco (etapa 8).

O processo seguinte é o entabuamento do casco seguindo as costelas, e do convés seguindo as latras, surgindo nessa etapa a superfície, finalizando assim a forma geral do bote triângulo de Icapuí.

\section{DISCUSSÃO}

Tal como na abordagem da arquitetura vernacular proposta por Cardoso (2010) o trabalho de pesquisa que se desenvolve na Universidade Federal do Ceará, pretende suscitar 0 uso de tal metodologia para documentação pelas instituições implicadas com a cultura e patrimônio.
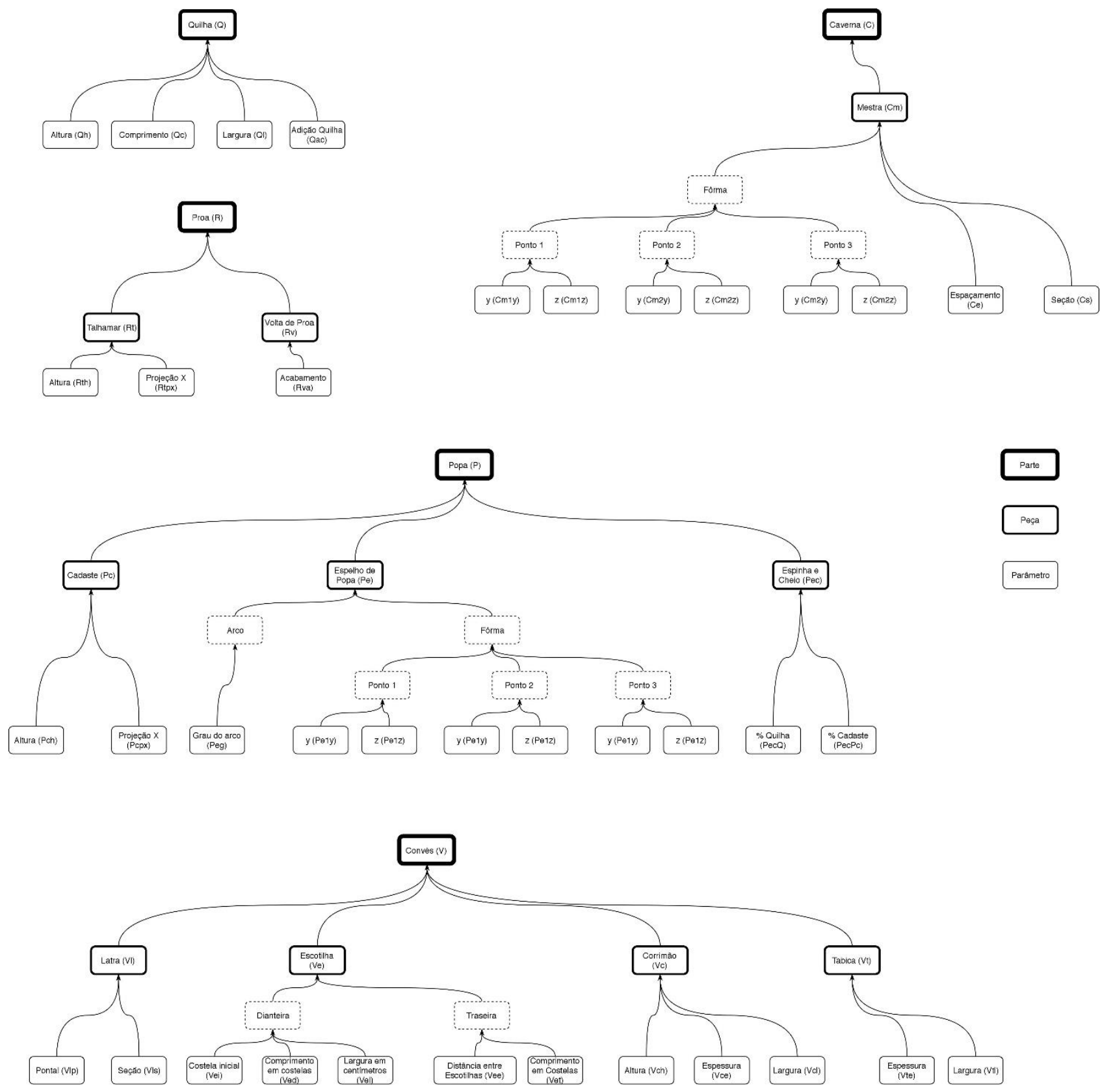

Figura 5: Diagrama demonstrando cadeia lógica e hierárquica de dados construídos na apreensão dos barcos, para sistematização. Fonte: autores. 
Segundo Gursoy (2015) "a construtibilidade de modelos digitais paramétricos usando baixa tecnologia e técnicas tradicionais de construção podem melhorar as práticas locais e induzir a designs otimizados em países emergentes." Com isso a atual pesquisa introduziu documentação paramétrica não apenas para fins patrimoniais, mas também incitando desdobramentos dos elementos obtidos, desde o retorno dos resultados aos pescadores, até a investigação de maneiras de incorporar metodologias e práticas vernaculares ao fazer do design contemporâneo.

Também é levantada a questão acerca de como caminhos simples e com poucos recursos podem resultar em profundas complexidades, tomando como objeto de estudo culturas locais.

\section{REFERÊNCIAS}

ANASTASSAKIS, Z. Vinculações entre Design e Cultura no Brasil: a outra vertente de LINA BO BARDI e ALOÍSIO MAGALHÃES em CAMARGO, Paula de Oliveira et al (Org.). Design e/é Patrimônio. Rio de Janeiro: G3 Gráfica e Editora Me, 2012.

ANASTASSAKIS, Zoy. Dentro e fora da política oficial de preservação do patrimônio cultural no Brasil: Aloísio Magalhães e o Centro Nacional de Referência Cultural. Rio de Janeiro: UFRJ, Museu Nacional, PPGAS, 2007.

ARAÚJO, Nearco; DUARTE JR., Romeu (Org.). Ventos, velas e veleiros: embarcações tradicionais do Ceará. 1. ed. Fortaleza: Modo Maior, 2014.
BARDI, Lina Bo. Tempos de grossura o design no impasse. São Paulo: Instituto Lina Bo e P. M. Bardi, 1994.

BRAGA, Miguel Sávio de Carvalho. Embarcações a vela do litoral do Estado do Ceará: construção, construtores, navegação e aspectos pesqueiros. Tese (doutorado) Universidade Federal do Ceará, Instituto de Ciências do Mar, Programa de Pós-Graduação em Ciências Marinhas Tropicais, Fortaleza, 2013.

CARDOSO, Daniel. Desenho de uma poiesis. Expressão Gráfica e Editora, Fortaleza, 2010.

DRESCH, A.; LACERDA, D. P.; ANTUNES JÚNIOR, J. A. V. Design Science Research: método de pesquisa para avanço da ciência e tecnologia. Porto Alegre: Bookman, 2015.

MAGALHÃES, Aloísio. In: O produto brasileiro começa a ter desenhada a sua fisionomia. Rio de Janeiro: O Globo, 05/01/1977.

MAGALHÃES, Aloísio. E Triunfo? A questão dos bens culturais no Brasil. Rio de Janeiro: Nova Fronteira; Fundação Roberto Marinho, 1997.

VAZQUEZ, Elena; DIARTE, Julio; GURSOY, Benay. (2018) Bridging parametric design and craftsman-ship. CAADRIA pg 3-8.

GURSOY, Benay. Visualizing making: Shapes materials and actions. Istanbul: Elsevier, 2015, pg 29-50.

IBAMA. Boletim Estatístico da pesca Marítima e Estuarina do Estado do Ceará - 1997. Tamandaré: Centro de Pesquisa e Gestão de Recursos Pesqueiros do Litoral Nordeste, 1998, pg 72. 